\title{
Parasitoid Telur Lalatjala (Chrysopa sp.) pada Ekosistem Jambu Mete di Lombok
}

\author{
BAMBANG SUPENO \\ Staff Pengajar Program Studi Hama dan Penyakit Tumbuhan \\ Jurusan Budidaya Pertanian, Fakultas Pertanian, Universitas Mataram
}

(diterima Agustus 2006, disetujui Januari 2007)

\begin{abstract}
Eggs Parasitoid of Green Lacewing (Chrysopa sp.) in Lombok Cashew Ecosystem. The objective of this research was to identify parasitoids associated with eggs of Chrysopa in Lombok cashew ecosytem. Parasitoids were surveyed by collecting eggs of Chrysopa from cashew plantations. A total of 5900 individual parasitoids from a single species were collected from eggs of Chrysopa with parasitization level ranging from approximately $47.0 \%-85.50 \%$. The parasitoid was identified as Telenomus cyrus (Hymenoptera: Scelionidae).

KEYWORDS: Chrysopa, parasitization, parasitoid, cashew, Telenomus.
\end{abstract}

\section{PENDAHULUAN}

Jambu mete di Nusa Tenggara

Barat dikembangkan secara intensif pada daerah-daerah lahan kritis dan kering yang terletak di pulau Lombok dan Sumbawa dengan tujuan untuk konservasi dan penghijaun tanah-tanah gundul (kering). Penghijauan ini dipusatkan di Lombok utara yang mencapai area seluas ratusan hektar sebagai tanaman penghijaun dan sekarang telah berproduksi sehingga pendapatan petani meningkat.

Pengembangan jambu mete di daerah ini mengalami beberapa kendala, diantaranya adalah berupa gangguan hama dan penyakit. Berdasarkan hasil pengamatan $\mathrm{di}$ lapangan oleh tim peneliti ditemukan beberapa hama yang cukup merugikan antara lain : Cricula trifenestrata. Nepoptherix sp., Helopeltis sp., Acrocercops sp., Lawana sp., Aphis sp. dan thrips. Supeno (2004a) melaporkan bahwa ada empat spesies hama penggorok daun di ekosistem jambu mete lahan kering Lombok. Namun hama wereng pucuk mete (Sanurus indecora Jacobi) merupakan hama yang dapat menimbulkan kerugian yang sangat berarti pada produksi mete. Sudarmadji (2004) melaporkan bahwa jumlah populasi $S$. indecora pada sistem tanam jambu mete dan pada ketinggian lokasi pertanaman yang berbeda. Supeno (2004b) mengatakan bahwa populasi telur $S$. indecora sekitar 27-355 kelompok telur per pohon. $S$. indecora 
menyerang pucuk-pucuk muda baik pada saat tidak musim berbunga maupun berbunga. Kerugian meningkat bila terjadi pada saat musim bunga serangan hama ini dapat menyebabkan bunga-bunga mengering. Hasil pengamatan Populasi wereng pucuk mete pada beberapa sentra produksi berbeda-beda dengan dan ratarata sekitar 450 ekor per tanaman. Hamdi (2004) mengatakan bahwa populasi telur $S$. indecora per pohon di Kecamatan Kayangan dan Bayan mencapai rata-rata 173,54 kelompok telur. Setiap kelompok telur rata-rata mengandung 132.56 butir. Haryanto \& Supeno (2003) melaporkan bahwa populasi imago atau serangga dewasa per pohon mete di dua kecamatan sentra produksi mete di pulau Lombok mencapai 634 - 789 ekor pada kondisi serangan berat.

Inang $S$. indecora di Lombok cukup banyak. Selain mete, hama ini juga menyerang mangga, jeruk, jambu air, belimbing, jambu biji, rambutan, sirsak dan cermai. Serangan terberat terjadi pada tanaman jeruk dan mangga dengan intensitas serangan rata-rata $76,66 \%$ (Syamsumar \& Haryanto 2003).

Seiring dengan populasi wereng mete yang tinggi, maka telah ditemukan berbagai jenis musuh alami yang berasosiasi dengan hama tersebut. Supeno (2004c) melaporkan bahwa satu spesies serangga dari Famili Epypiropidae berasosiasi dengan imago $S$. indecora sebagai ektoparasitoid. Selain itu, Supeno (2004) dan Supeno (2004e) menemukan empat predator dan dua parasitoid yang berasosiasi dengan telur S. indecora. Empat predator telur tersebut adalah serangga-serangga dari ordo Diptera, Coleoptera, Hymenoptera, dan Neuroptera. Pemangsa telur, yang diidentifikasi sebagai Chrysopa sp. (Neuroptera: Chjrysopidae), merupakan pemangsa yang paling dominan di lapang. Chrysopa sp. yang dikenal sebagai lalatjala mempunyai potensi untuk dijadikan sebagai agen pengendali hayati. Larva lalatjala mampu memangsa 3-12 ekor mangsa kutu dalam waktu 24 jam, atau setiap koloni kutu yang terdiri 15-20 ekor dapat dihabiskan oleh seekor lalatjala dalam waktu 2-16 hari (Sumardja 1994). Nur Indah Sari (2005 komunikasi pribadi) menginformasikan bahwa larva lalatjala selama 14 hari mampu menghabiskan telur $S$. indecora sebanyak 158 butir. Kemampuan memangsa rata-rata per hari 11,28 butir.

Peran lalatjala tampak besar potensinya sebagai agens pengendali hayati hama wereng pucuk mete, namun disisi lain dalam kehidupan di alam tidak terlepas dari incaran pemangsa dalam rantai makanan di atasnya. Berdasarkan hasil pengamatan di lapangan, telur-telur lalatjala terparasit oleh serangga lain. Jenis dan populasinya parasitoid 
tersebut belum diketahui dengan jelas sehingga dilakukan penelitian. Penelitian ini bertujuan untuk mengidentifikasi parasitoid yang berasosiasi dengan telur lalatjala, dan mempelajari keberadaannya di lapangan pada ekosistem mete lahan kering Lombok.

\section{BAHAN DAN METODE}

\section{Tempat dan Waktu Penelitian}

Penelitian dilakukan di tiga kecamatan yang berada di wilayah Kabupaten Lombok Barat. Ketiga kecamatan tersebut merupakan daerah pusat pertanaman mete di pulau Lombok, yaitu Gangga, Kayangan dan Bayan. Penelitian dilaksanakan pada bulan Mei hingga Juli 2005.

\section{Penentuan Lokasi Penelitian}

Lokasi penelitian ditentukan berdasarkan luas daerah pertanaman mete yang dimiliki di masing-masing kecamatan. Lokasi penelitian tersebut terdapat di tiga desa yang memiliki pertanaman mete terbanyak di masingmasing kecamatan. Ketiga desa tersebut adalah Sambik Bangkol, Salut, dan Loloan.

\section{Teknik Penentuan Tanaman Contoh}

Pengambilan sampel dilakukan dengan teknik transek dengan 5 situs pada setiap lokasi sehingga ada 15 situs. Jarak antara situs satu dengan lainnya sekitar 1.000 meter. Pada setiap situs ditentukan 3 pohon mete yang terserang oleh wereng mete (Samurus indecora), sehingga secara keseluruhan diperoleh 45 unit sampel pohon mete.

\section{Penentuan Lokasi Pengambilan Contoh}

Contoh telur lalatjala diambil pada 24 ranting per pohon yang ditentukan secara acak pada empat arah mata angin (Barat, Timur, Utara dan Selatan). Secara keseluruhan di setiap lokasi pengamatan diperoleh 360 ranting contoh sebagai tempat untuk pengambilan telur Chrysopa sp.

\section{Pengambilan Contoh}

Telur lalatjala yang terdapat pada setiap ranting mete diambil beserta bagian tanaman tempat melekatnya tangkai telur lalatjala. Telur diambil dengan menggunakan gunting kemudian dimasukkan ke dalam botol koleksi dan diberi label. Telur-telur hasil koleksi di lapangan dibawa ke laboratorium untuk dipelihara dan disortasi.

\section{Pemeliharaan Telur Lalatjala}

Telur hasil koleksi dari lapangan dimasukkan dalam tabung reaksi bertutup karet atau gabus dan disimpan dalam suhu kamar. Untuk mencegah gangguan semut pada telur digunakan kapur semut pada wadah koleksi tabung reaksi. Setiap hari telur diamati sampai semua telur habis menetas. 


\section{Pemisahan Parasitoid}

Parasitoid yang muncul dari telur lalatjala dimatikan, dihitung, dan dipisahkan berdasarkan ciri-ciri morfologinya, kemudian disimpan dalam cairan alkohol $70 \%$.

\section{Pengamatan Karakteristik Morfologi Parasitoid}

Pengamatan morfologi imago parasitoid yang keluar meliputi karakter yang ada pada kepala torak dan abdomen. Ukuran tubuh, wama pada masing-masing jenis kelamin parasitoid.

\section{Identifikasi}

Karakter morfologi yang diperoleh dibandingkan dengan buku kunci identifikasi karangan Goulet and Huber (1993). Borror and White (1970), Nixon (1937) dan Naman (1991).

\section{HASIL DAN PEMBAHASAN}

\section{Gejala Telur Terparasit}

Telur lalatjala yang ditemukan pada ekosistem jambu mete di pulau Lombok berbentuk oval dan bertangkai. Telur berwarna kuning kehijauan, dan berukuran panjang sekitar $1 \mathrm{~mm}$ (Gambar la). Tangkai telur seperti benang, berwarna putih dan panjangnya sckitar $5 \mathrm{~mm}$. Telur diletakkan menempel pada daun atau ranting dekat dengan koloni telur hama wereng mete. Telur yang terparasit dicirikan oleh warna telur yang berubah dari hijau kekuningan menjadi coklat, ungu, abuabu, kuning atau hitam (Gambar Ib). Parasitoid muneul dari telur inang dengan cara membuat lubang bulat di bagian ujung telur yang kecil dan meninggalkan potongan kulit telur tidak terputus schingga tampak seperti tutup. Bila tutup-tutup tersebut lepas, maka akan tampak lubang keluarnya parasitoid tersebut (Gambar lc).

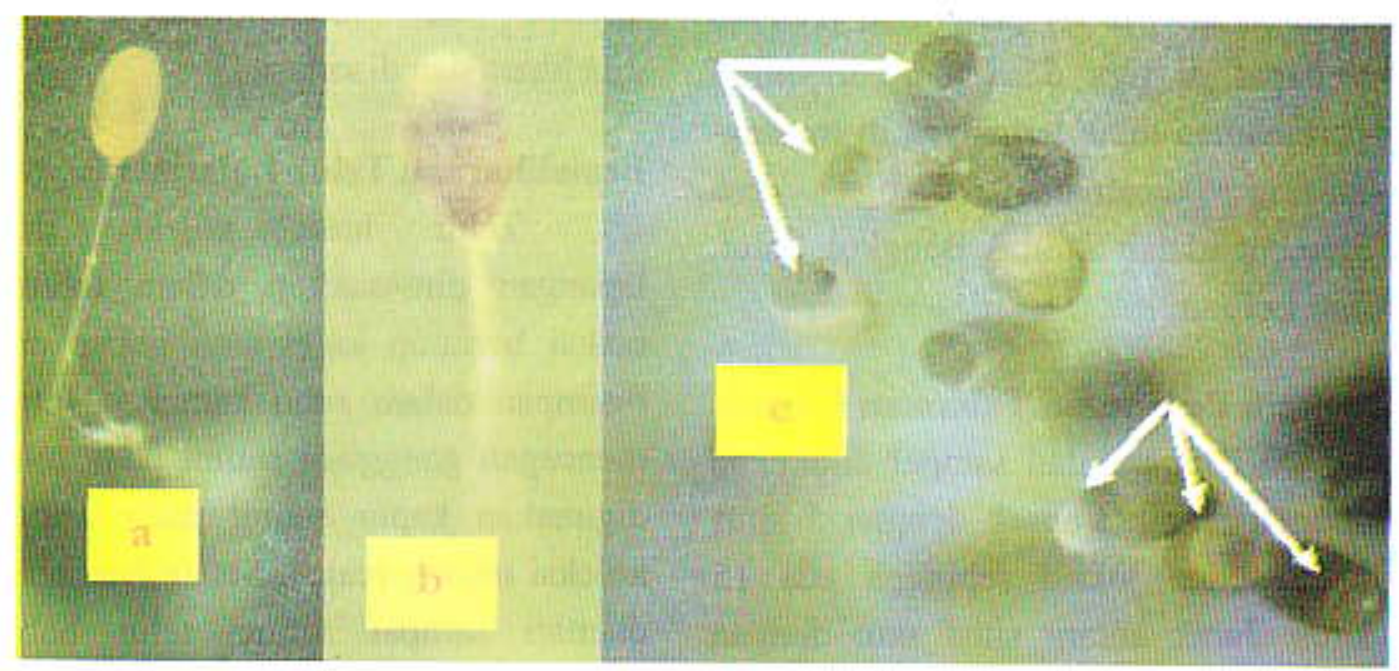

Gambar 1. Telur lalatjala (Chrysopa sp.) sehat (a) dan terparasit (b dan c) 


\section{Karakter Morfologi}

Pengamatan di laboratorium terhadap morfologi parasitoid telur lalatjala menemukan hanya satu spesies parasitoid. Parasitoid tersebut tergolong dalam ordo Hymenoptera. Ukuran parasitoid kecil sekali sekitar $0,7-1 \mathrm{~mm}$, warna tubuh hitam, mata juga berwarna hitam dan memiliki tiga oseli yang berwarna merah. Antena berwarna coklat kehitaman berbentuk filiform, beruas 10 untuk betina dan 11 ruas untuk jantan. Skapus memanjang dan membentuk siku atau menyudut dengan adanya bulu-bulu atau sensori. Sayap depan bervenasi tereduksi dengan venasi marginal mencapai anterior sayap. memiliki stigmal dan postmarginal pendek.

Trokanter terdiri atas dua ruas, tungkai belakang paling panjang dibandingkan dengan yang lainnya. Tarsus tungkai belakang lebih panjang dibandingkan dengan tibia. Abdomen tampak bagian tergum dan sternum bertemu di samping, ovipositor masuk dalam metasoma. Tergum memiliki tujuh ruas dengan ruas ke ke tiga yang terpanjang dari ruas yang lainnya.

Berdasarkan karakter morfologi tersebut di atas parasitoid telur tersebut menurut buku identifikasi The Insects of Australia : a Texbook for Student and Research Worker di kelompokkan dalam Subordo Aprocrita Superfamili Platygastroidea. Demikian juga menurut Goulet \& Huber (1993) dikelompokkan dalam Superfamili yang sama. Ciri khas dari superfamili ini ditunjukkan oleh adanya bagian tergum dan sternum yang menyatu atau bertemu di samping membentuk garis memipih. Berdasarkan ukuran tubuh yang mini atau kecil berwarna hitam, bentuk antena dengan ruas flagelomer 10-11, vena marginal sayap depan yang mencapai pangkal anterior dan memiliki stigmal serta postmarginal yang sangat pendek, maka dikelompokkan dalam famili Scelonidae (Masner 1993). Dengan jumlah ruas antena 10-11 merupakan salah satu karakter yang membedakan Genus Telenomus dengan Genus lainnya dalam satu famili (Nixon 1937). Adanya bentuk tungkai yang panjang dan ramping serta ukuran tarsus tungkai belakang yang lebih panjang dari tibia tungkai belakang (Gambar 2), merupakan ciri khas dari spesies Telenomus cyrus. Parasitoid spesies ini juga telah dilaporkan menyerang telur Nezara viridula L. di LembangBandung (Nixon 1937).

\section{Populasi Parasitoid Telur}

Jumlah telur lalatjala yang terparasit (tingkat parasitasi) tampak relatif berbeda pada tiga lokasi penelitian. Tingkat parasitasi yang terjadi di lapangan berkisar antara $47,0 \%$ hingga $85,5 \%$ (Tabel 1). Kondisi ini terkait dengan faktor inang (makanan) yang tersedia untuk berkembangbiak bagi parasitoid lalatjala tersebut. Keadaan ini selaras 


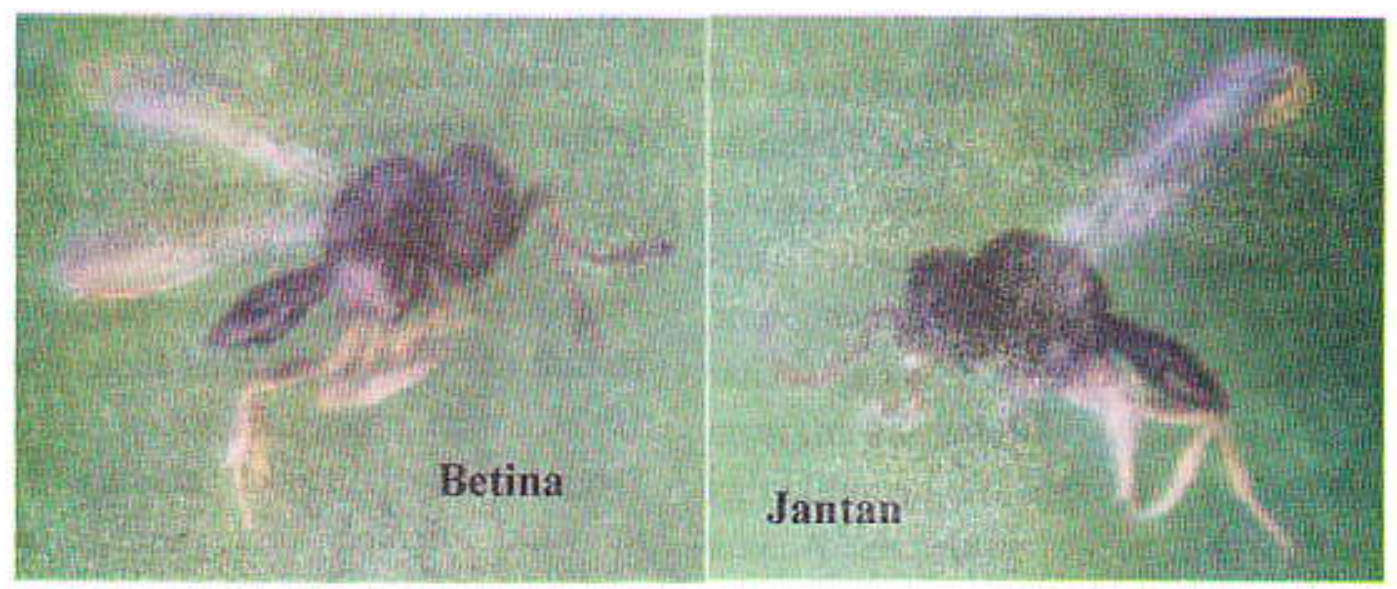

Gambar 2. Parasitod Telenomus cyrus yang menyerang telur lalatjala (Crysopha sp.) pada ekosistem jambu mete di Lombok

Tabel 1. Jumlah telur lalatjala terparasit dan tingkat parasitasi di tiga lokasi penelitian

\begin{tabular}{lcccc}
\hline \multirow{2}{*}{ Lokasi Pengamatan } & \multicolumn{3}{c}{ Jumlah telur } & Parasitisasi \\
\cline { 2 - 4 } & Terparasit & Tidak Terparasit & Total & $(\%)$ \\
\hline Gangga & 1902 & 852 & 2766 & 68,8 \\
Kayangan & 2260 & 383 & 2643 & 85.5 \\
Bayan & 738 & 832 & 1570 & 47,0 \\
\hline
\end{tabular}

dengan laporan Rahardjo (2004) yang menunjukkan bahwa populasi imago $S$. indecora tertinggi terdapat di Kayangan, yaitu 417,75 ekor/pohon, diikuti dengan di Gangga sebesar 63,67 ekor/pohon, dan terendah di Bayan dengan 52,29 ekor/pohon. Keberhasilan proses parasitasi olch parasitoid ini sangat ditentukan oleh beberapa faktor seperti inang, habitat, dan kesesuaian inang yang diparasit (Arthur 1981).

\section{KESIMPULAN}

Berdasarkan hasil pengamatan di tiga kecamatan di Kabupaten Lombok Barat dapat disimpulkan bahwa parasitoid yang berasosiasi dengan telur Chrysopa sp. di ekosistem jambu mete di Pulau Lombok hanya ada satu spesies, yaitu Telenomus cyrus, famili Scelionidae, superfamili Platygastroidea, ordo Hymenoptera. Telenomus cyrus merupakan parasitoid soliter. Tingkat parasitasi yang terjadi di lapangan berkisar $47,0 \%$ hingga $85,5 \%$.

\section{DAFTAR PUSTAKA}

Alrouechdi K, Y Semeria, T R New. 1984. Ecology of Natural Enemies. p 187193 in M Canard, Y Semeria, New T R, 1984. Biology of Chrysopidae, DR.W.Junk Publishers, the Hague. Netherland.

Arthur AP. 1981. Host Acceptance By Parasitoid. p 97-120. in Nordlind. DA, Jones R.L, Lewis WJ. 1981. Semiochemicals : Their Role In Pest 
Control. New York: John Wiley and Sons.

Borror DJ, White RE. 1970. Field Guide to The insects. Boston: Houghton Mifflin Company..

Goulet H, Huber JT. 1993. Hymenoptera of the World : An identification guide to families. Ottawa: Agricultural Canada.

Hamdi ZL, Supeno B, Haryanto H. 2004. Identifikasi Parasitoid Telur Hama Wereng Jambu Mete (Samurus indecora. Jacobi.) di Areal Perkembunan Pulau Lombok. . Jurnal Penelitian Hapete. 1(1): 1826.

Nauman LD. 1991. Hymenoptera (Wasp, Bees, Ants, Sawflies). p 916-1000. Division of Entomology Commonwealth and Industrial Research Organitation (Ed.). Volume II. The Insects of Australia : a Texbook for Student and Research Worker. Melborne University Press.

New T R. 1984. Identification of Hymenopterous parasites of Chrysopidae p 193-205. in M Canard, Y Semeria, New T R, 1984. Biology of Chrysopidac. DR.W.Junk Publishers, the Hague, Netherland.

Nixon GEJ. 1937. Some Asiatic Telenominae (Hymenoptera:Proctotrupoidea). Ann. And Mang. Nat, Hist. 10 (20): 444-475.

Masner L. 1993. Superfamily Platygastroidea. P 558-565, in Goulet H., Huber JT. 1993. Hymenoptera of the World: An identification guide to families. Ottawa: Agricultural Canada.

Sudarmadji R. 2004. Dinamika Populasi Sanurus indecora.J. Pada Tanaman Jambu Mete di Nusa Tenggara Barat. Prosiding Seminar Nasional. Entomologi Dalam Perubahan Lingkungan Dan Sosial. p 599-610.

Supeno B. 2004. Predator dan parasitoid telur yang berasosiasi dengan telur wereng jambu mete (Sanurus indecora Jacobi.) di Perkebunan Jambu Mete Lombok Utara. Jurnal
Penelitian Lembaga Pusat Penelitian Universitas Mataram.

Supeno B. 2004a. Potensi Aphanomerus sp. (Hymenoptera : Platygastridae) Sebagai Parasitoid Telur Wereng Mete (Sanurus Indecora). Jurnal Penelitian Universitas Mataram. Vol 2, No. 6. Edisi A : Sains dan Teknologi. p 216-220

Supeno B. 2004b. Parasitoid Yang Berasosiasi Dengan Imago Wereng Jambu Mete (Samurus Indecora J.) Di Perkebunan Jambu Mete Lombok Utara. Agroteksos. Volume 14 No.2. p. $62-67$

Supeno B. 2004c. Keberadaan Hama Peliang Daun Jambu Mete (Cashew Leaf Miner) Pada Tiga Sistem Tanam Di Lahan Kering Pulau Lombok. Prosiding Seminar Nasional. Entomologi Dalam Perubahan Lingkungan Dan Sosial. p 549-558.

Supeno B. 2004d. Keberadaan Famili Epipyropidae Sebagai Ektoparasitoid Pada Imago Wereng Jambu Mete (Sanurus Indecora Jacobi) Di Ekosistem Jambu Mete Lahan Kering Lombok . Prosiding Seminar Nasional. Entomologi Dalam Perubahan Lingkungan Dan Sosial. p 117-128.

Syamsumar DL, Supeno B, Haryanto H. 2004. Potensi Parasitoid Telur Aphanomerus sp. sebagai Agen Pengendali Hayati Hama Wereng Jambu Mete (Samururus indecora Jacobi.). Jurnal Penelitian Hapete. 1(1) $: 9-17$

Syamsumar DL, Haryanto H, 2003. Distribusi Hama Lawana candida pada beberapa jenis tanaman perkebunan di Kabupaten Lombok Barat. Makalah Seminar Nasional Kongres VI PEI dan Simposium Entomologi, Cipayung-Bogor, 5-7 Maret 2003.

Sumardja. 1994. Peluang Bisnis Keanekaragaman Hayati Serangga Nusantara. Kantor Menteri Lingkungan Hidup Environmental Management Development In Indonesia Perhimpunan Entomologi Indonesia. Jakarta. 